\title{
Effects of profound acidemia on the dynamic glucose and insulin response and plasma potassium and phosphorus concentrations during an intravenous glucose tolerance test in neonatal calves
}

\author{
F. M. Trefz, ${ }^{* 1}$ I. Lorenz, † and P. D. Constableł \\ ${ }^{*}$ Clinic for Ruminants with Ambulatory and Herd Health Services at the Centre for Clinical Veterinary Medicine, \\ Ludwig-Maximilians-Universität (LMU) Munich, Sonnenstraße 16, 85764 Oberschleißheim, Germany \\ †Bavarian Animal Health Service (Tiergesundheitsdienst Bayern e.V.), Senator-Gerauer-Str. 23, 85586 Poing, Germany \\ †College of Veterinary Medicine, University of Illinois, Urbana-Champaign 61802
}

\section{ABSTRACT}

Acidemia and electrolyte imbalances such as hyperkalemia are common in neonatal calves with diarrhea. Acidemia negatively affects the cellular response to insulin and may therefore result in deranged glucose, potassium, and phosphorus homeostasis. The primary aim of this study was to compare indices that characterize the dynamic glucose and insulin response between acidemic and nonacidemic neonatal diarrheic calves and a healthy control group during an intravenous glucose tolerance test (IVGTT) that consisted of i.v. administration of $0.3 \mathrm{~g}$ of glucose per $\mathrm{kg}$ of body weight. Secondary aims were to characterize the associated changes in plasma potassium and phosphorus concentrations. The effect of correction of profound acidemia with a sodium bicarbonate containing infusion on these parameters was also assessed. Thirty calves (age $\leq 21$ d) were purposively assigned to one of the following groups: 10 calves with diarrhea and profound acidemia (venous blood $\mathrm{pH}<7.20$ ) where an IVGTT was performed before and after treatment with sodium bicarbonate, 10 calves with diarrhea and minimal acid-base disturbance (venous blood $\mathrm{pH}>7.35$ ), and 10 healthy control calves. Profoundly acidemic diarrheic calves (jugular venous blood $\mathrm{pH} 6.99 \pm 0.10$ ) had a similar initial increase in plasma insulin concentration to that in healthy control calves or nonacidemic calves with diarrhea. However, insulin concentrations remained relatively stable in acidemic calves between 15 and 60 min after the start of the IVGTT, whereas a marked decrease in plasma insulin concentrations occurred in all other groups during the same period of time. We conclude that acidemia does not alter cell glucose availability or the dynamic response of glucose, phosphorus, and potassium to insulin; however, acidemia markedly

Received February 5, 2017.

Accepted July 21, 2017.

${ }^{1}$ Corresponding author: Florian.Trefz@campus.lmu.de prolongs plasma insulin concentrations following an IVGTT through an unidentified mechanism. Results of this study emphasize the importance of correcting acidemia and metabolic acidosis in neonatal calves with diarrhea.

Key words: calves, insulin resistance, glucose, potassium, phosphorus

\section{INTRODUCTION}

Dehydration, azotemia, and development of a hyponatremic strong ion (metabolic) acidosis with variable degrees of hyper D-lactatemia are well-known complications in neonatal calves with diarrhea (Lorenz, 2004; Constable et al., 2005; Trefz et al., 2015a). Electrolyte imbalances such as hyperkalemia are also common in diarrheic calves and can result in skeletal muscle weakness and life-threatening cardiac conduction abnormalities and arrhythmias (Lewis and Phillips, 1973; Weldon et al., 1992; Trefz et al., 2013b).

Potassium is predominantly an intracellular cation and hyperkalemia in neonatal diarrheic calves has traditionally been attributed to an acidemia-induced dysregulation of internal potassium balance. Intracellular buffering of hydrogen ions and impaired $\mathrm{Na}^{+} /$ $\mathrm{K}^{+}$-ATPase activity have therefore been proposed as underlying mechanisms for hyperkalemia in diarrheic calves (Lewis and Phillips, 1973; Sweeney, 1999; Constable, 2002). However, recent research indicates that the occurrence of hyperkalemia in neonatal diarrheic calves is primarily dependent on the degree of dehydration and to a lesser extent on the cause of the acidemia (Trefz et al., 2013a,b). Decreased renal perfusion and glomerular filtration rate therefore appear to play decisive roles in the development of hyperkalemia. Nevertheless, other factors still have the potential to play an important pathophysiological role in the development of hyperkalemia in diarrheic calves.

The mechanism linking acidemia and altered intracellular potassium homeostasis is not fully understood. 
Insulin is involved in the regulation of internal potassium balance by providing a net cellular uptake of potassium (Cox et al., 1978; Bia and DeFronzo, 1981). As even mild acidemia (blood $\mathrm{pH}, 7.27 \pm 0.01$ and 7.37 \pm 0.02 ) has been associated with insulin resistance in humans (DeFronzo and Beckles, 1979; Mak, 1998), it is likely that insulin-dependent cellular potassium uptake is impaired in the presence of acidemia (Constable and Grünberg, 2013). Impaired cellular responsiveness to insulin provides a potential explanation for the association between acidemia and hyperkalemia. Feeding a low DCAD ( $-41 \mathrm{mEq} / 100 \mathrm{~g})$ ration to nonlactating nonpregnant dairy cows induced acidemia (blood $\mathrm{pH}$, 7.32), metabolic acidosis (plasma $\mathrm{HCO}_{3}{ }^{-}, 17.8 \mathrm{mmol} / \mathrm{L}$; urine $\mathrm{pH}, 5.4$ ), and decreased insulin responsiveness, as assessed by higher peak plasma glucose and lower peak plasma insulin concentrations in response to an intravenous glucose tolerance test (IVGTT; Bigner et al., 1996). We therefore hypothesized that neonatal calves with diarrhea and profound acidemia and hyperkalemia have decreased insulin responsiveness and a slower rate of decrease in plasma potassium concentration, compared with diarrheic calves with minimal disturbances in acid-base balance and healthy calves without diarrhea.

Combined administration of insulin and glucose is a well-established treatment for hyperkalemia in humans (Weisberg, 2008). Evaluation of indices that characterize the dynamic glucose and insulin response to an IVGTT in acidemic neonatal calves should improve our understanding of the pathophysiology of potassium balance disorders in neonatal calves with diarrhea and therefore improve treatment protocols for hyperkalemia in acidemic calves. Although it is well known that restoration of potassium homeostasis in diarrheic acidemic calves can be achieved by rehydration and alkalinization using intravenous solutions containing sodium bicarbonate (Koch and Kaske, 2008; Coskun et al., 2010; Trefz et al., 2015b), we hypothesized that intravenous administration of a glucose-containing solution induces endogenous insulin release and thereby exerts a potassium-lowering effect. This might be especially of relevance in the initial treatment of affected calves, where treatment objectives focus on the rapid correction of hyperkalemia, hypoglycemia, and profound acidemia (Constable and Grünberg, 2013; Lorenz and Trefz, 2016). This research question is also of interest because administration of glucose containing infusion solutions to diarrheic calves that require intravenous fluid therapy is popular in ambulatory field practice. Intravenous glucose is administered to counteract negative energy balance and provide a readily utilizable energy source when calves are housed in cold ambient conditions (Berchtold, 2009).
The major objectives of the study reported here were therefore to administer an IVGTT to characterize the dynamic glucose and insulin response and changes in plasma potassium concentrations between acidemic and nonacidemic neonatal diarrheic calves and a healthy control group. Because insulin also induces a compartmental shift of inorganic phosphorus $\left(\mathbf{P}_{\mathbf{i}}\right)$ into insulinresponsive cells in cattle (Knochel, 1977; Grünberg et al., 2006) by upregulating $\mathrm{Na} / \mathrm{P}_{\mathrm{i}}$ co-transporter gene expression ( $\mathrm{Li}$ et al., 1996), we also examined the $\mathrm{P}_{\mathrm{i}}$ concentration-time relationship during an IVGTT. An additional objective was to determine whether correction of profound acidemia with a sodium bicarbonatecontaining infusion has an immediate effect on these parameters.

\section{MATERIALS AND METHODS}

The methods of this study were approved by the Animal Welfare and Ethics Committee of the government of Upper Bavaria (permit: 55.2-1-54-2532-11-14) according to German Animal Welfare Legislation.

\section{Calves}

An IVGTT was performed in 30 neonatal calves up to $21 \mathrm{~d}$ of age. Calves were purposively selected to be assigned to one of the following 3 groups:

1. Ten calves with diarrhea and profound acidemia (venous blood $\mathrm{pH}<7.20$; acidemic group; group A). An IVGTT was performed before treatment (A-BT) and after treatment (A-AT) with intravenous sodium bicarbonate as described below.

2. Ten calves with diarrhea and minimal acid-base disturbance (venous blood $\mathrm{pH}>7.35$; nonacidemic group; group NA).

3. Ten healthy calves with normal fecal consistency and volume (control group; group $\mathbf{C}$ ).

Before inclusion into the study, calves underwent a thorough physical examination that included the assessment of the general condition and examination of the respiratory, gastrointestinal, and cardiovascular system as well as palpation of navel structures and joints. Physical examination included the clinical assessment of posture/ability to stand, behavior, rectal temperature, and extent of enophthalmos (mm). Physical examination was repeated in calves of group A before start of the second IVGTT. Posture was scored as $1=$ standing securely; 2 = insecurely, able to correct position; $3=$ insecurely, unable to correct position; and $4=$ unable to stand. Behavior was scored as $1=$ adequate reaction, very bright and alert; $2=$ adequate reaction; 
$3=$ delayed reaction; $4=$ calf reacts only to painful stimuli; and $5=$ no reaction to painful stimuli. The severity of enophthalmos was quantified by measuring the distance $(\mathrm{mm})$ between the medial canthus and the eyeball (Constable et al., 1998; Niethammer, 2007). Diarrhea was defined as fecal consistency that allowed feces to run through slightly open fingers (Trefz et al., 2015a).

Exclusion criteria for calves assigned to groups A and NA were severe hypothermia (rectal temperature $<37^{\circ} \mathrm{C}$ ), severe hypoglycemia (plasma glucose concentration $<2.5 \mathrm{mmol} / \mathrm{L}$ ), severe clinical dehydration (degree of enophthalmos $>6 \mathrm{~mm}$ ), venous blood $\mathrm{pH}$ $<6.80$, and severe concurrent health problems including obvious signs of septicemia, navel infections requiring surgical intervention or clinical evidence of pneumonia.

To avoid breed-specific differences on the dynamic glucose and insulin response to an IVGTT (Bossaert et al., 2009), only calves of the Simmental breed (German Fleckvieh; the most common dairy breed in Bavaria) were included in the study. All experiments were performed at the Clinic for Ruminants with Ambulatory and Herd Health Services, Ludwig-Maximilians-Universität (LMU) Munich. A total of 9 calves of group C, 3 calves of group NA, and 1 calf of group A were obtained from the teaching and research farm of LMU Munich, which is located within $500 \mathrm{~m}$ of the Clinic for Ruminants, and were transported to the hospital on the day of the experiment. The remaining calves were recruited from the patient pool of the Clinic for Ruminants. Written informed consent was obtained from the owners of calves before inclusion in the study.

\section{Experimental Protocol}

Calves were weighed before the trial and all experiments were performed at least $6 \mathrm{~h}$ after the last milk feeding, based on reports by the owners of calves. A 16-gauge, 15-cm catheter (Splittocan Infusionskatheter, Walter Veterinär Instrumente, Baruth, Germany) was placed in a jugular vein, which was introduced through a 14-gauge Splittocan cannula and used for glucose infusion and blood sampling. For this purpose, the area over the respective jugular vein was clipped, aseptically prepared, and $2 \mathrm{~mL}$ of a $2 \%$ procaine solution injected into and under the skin before catheterization. The catheter set contained a 13-cm elongation tube, which was used to avoid manipulation of calves during blood sampling. After catheter placement, calves were allowed to rest for at least $30 \mathrm{~min}$ until blood sampling began.

The IVGTT consisted of an i.v. infusion of $0.3 \mathrm{~g}$ of glucose $/ \mathrm{kg}$ of $\mathrm{BW}$ administered over a period of $1 \mathrm{~min}$ (equivalent to $0.75 \mathrm{~mL}$ of a $40 \%$ glucose solution per $\mathrm{kg}$ of BW; $400 \mathrm{~g} / \mathrm{L}$ glucose anhydrous, B. Braun Melsun- gen AG, Melsungen, Germany). Lithium-heparinized blood samples were anaerobically collected at $-15,0,3$, $6,10,15,20,30,40,50,60,75,90$, and 120 min relative to the onset of the infusion. After glucose infusion and blood sampling the catheter was flushed with $5 \mathrm{~mL}$ of a $0.9 \% \mathrm{NaCl}$ solution.

At time $(\mathrm{t})=120 \mathrm{~min}$, the experiment was finished for calves of group NA and C. In calves of group A, correction of profound acidemia was then carried out by an infusion containing an amount of sodium bicarbonate, which was calculated according to following formula: $\mathrm{NaHCO}_{3}(\mathrm{mmol})=\mathrm{BW}(\mathrm{kg}) \times$ base deficit $(\mathrm{mmol} / \mathrm{L}) \times 0.7$. For this purpose, the required volume of a commercially available $8.4 \%$ sodium bicarbonate solution was diluted with sterile water (Ampuwa, Fresenius Kabi GmbH, Germany) to a volume of $2.5 \mathrm{~L}$ and the resulting infusion solution was administered over a period of $2.5 \mathrm{~h}$ as described by Lorenz and Vogt (2006). After completion of the infusion, calves were reweighed and the IVGTT repeated after an additional period of 30 min as described above.

\section{Laboratory Analyses}

Blood samples were kept at room temperature until determination of blood $\mathrm{pH}$, partial pressure of carbon dioxide $\left(\mathbf{p C O}_{2}\right)$, sodium, chloride, potassium, and ionized calcium concentrations within $10 \mathrm{~min}$ after collection using a blood $\mathrm{pH}$, gas, and electrolyte analyzer with ion selective electrodes (Rapidpoint 405, Siemens Healthcare Diagnostics, Tarrytown, NY). Blood pH and $\mathrm{pCO}_{2}$ were corrected for rectal temperature using standard algorithms (Thomas, 1972). Actual bicarbonate concentration $\left(c \mathrm{HCO}_{3}{ }^{-}\right)$was automatically calculated by the blood gas unit using the Henderson-Hasselbalch equation with measured blood $\mathrm{pH}$ and $\mathrm{pCO}_{2}$ at $37^{\circ} \mathrm{C}$ : $c \mathrm{HCO}_{3}{ }^{-}=S \times \mathrm{pCO}_{2} \times 10^{\left(\mathrm{pH}-\mathrm{pK} 1^{\prime}\right)}$. Values for the negative logarithm of the dissociation constant of carbonic acid $\left(\mathrm{pK}_{1}{ }^{\prime}\right)$ and solubility of carbon dioxide $(S)$ for plasma were 6.105 and $0.0307 \mathrm{mmol} / \mathrm{L}$ per $\mathrm{mm}$ of $\mathrm{Hg}$, respectively. After measuring the hemoglobin concentration $(\mathrm{Hb}$ in $\mathrm{g} / \mathrm{dL}$ ) photometrically, blood base excess (in vitro base excess) was automatically calculated in units of $\mathrm{mmol} / \mathrm{L}$ with measured blood $\mathrm{pH}$ at $37^{\circ} \mathrm{C}$ and the determined actual bicarbonate concentration $($ CLSI, 2009): base excess $=(1-0.014 \times c \mathrm{Hb}) \times$ $\left[\left(c \mathrm{HCO}_{3}{ }^{-}-24.8\right)+(1.43 \times c \mathrm{Hb}+7.7) \times(\mathrm{pH}-7.4)\right]$. After blood gas analysis, syringes were placed in a refrigerator and centrifuged within 30 min after collection at $1,500 \times g$ for $10 \mathrm{~min}$. Harvested plasma samples were assayed for glucose (hexokinase), $\mathrm{P}_{\mathrm{i}}$ (molybdenum), and insulin at all sampling times. Plasma concentrations of urea (urease), creatinine (picric acid), D-lactate (D-lactate dehydrogenase), L-lactate (L-lactate dehy- 
drogenase), and total protein (biuret) were additionally determined at $\mathrm{t}=-15 \mathrm{~min}$. An automatic analyzing system (Cobas c 311, Roche Diagnostics, Mannheim, Germany) was used for biochemical analysis. Plasma insulin concentrations were determined in duplicate using a commercially available ELISA kit (Bovine Insulin ELISA, EIA-4748, DRG Instruments, Marburg, Germany; provided by Mercodia, Uppsala, Sweden). For the latter, plasma samples were stored at $-25^{\circ} \mathrm{C}$ until analysis. Reported inter- and intraassay coefficients of variation of this assay were $\leq 7.0$ and $\leq 5.3 \%$, respectively. Plasma insulin concentrations were determined as $\mu \mathrm{g} / \mathrm{L}$ and converted for the present analysis to $\mu \mathrm{IU} /$ $\mathrm{mL}$ by multiplying values by 20.56 (Abuelo et al., 2012). Due to recommendations of the test provider, insulin concentrations below a concentration of $1.03 \mu \mathrm{IU} / \mathrm{mL}$ $(0.05 \mu \mathrm{g} / \mathrm{L})$ were not calculated from the calibration curve and were assigned a concentration $1.03 \mu \mathrm{IU} / \mathrm{mL}$. This was true for 63 out of 560 samples including 25 samples between $\mathrm{t}=-15 \mathrm{~min}$ and $3 \mathrm{~min}$ as well as 37 samples between $\mathrm{t}=30 \mathrm{~min}$ and $120 \mathrm{~min}$ in groups A-BT, NA, and A-AT. In group C, one sample was assigned a value of $1.03 \mu \mathrm{IU} / \mathrm{mL}$ at $\mathrm{t}=90 \mathrm{~min}$.

Baseline concentrations of glucose (Baseline $\mathrm{Glucose}_{\text {e }}$ ), insulin $\left(\right.$ Baseline $\left._{\text {Insulin }}\right)$, potassium $\left(\right.$ Baseline $\left._{\mathrm{K}}\right)$, and phosphorus (Baseline $\mathrm{Pi}_{\mathrm{Pi}}$ ) were calculated by averaging values from samples taken at $\mathrm{t}=-15 \mathrm{~min}$ and $0 \mathrm{~min}$ relative to the onset of glucose injection.

The percent change of plasma volume after treatment in calves of group A was extrapolated from the change of plasma total protein concentrations measured at baseline of each IVGTT before [(total protein $)_{\mathrm{BT}}$ ] and after treatment [(total protein $\left.)_{\mathrm{AT}}\right]$ with sodium bicarbonate, such that (Van Beaumont et al., 1972): $\Delta$ Plasma volume $=\left[(\text { total protein })_{\mathrm{BT}}-(\text { total protein })_{\mathrm{AT}}\right]$ $\times 100 /(\text { total protein })_{\mathrm{AT}}$.

\section{Analysis of Glucose Kinetics}

Peak concentrations for glucose $\left(\right.$ Peak $\left._{\text {Glucose }}\right)$ were determined from individual plasma glucose concentration-time curves. The area under the plasma glucose concentration-time curve $\left(\mathrm{AUC}_{\mathrm{Gluc}-60}\right)$ from 0 to $60 \mathrm{~min}$ after the start of dextrose infusion was calculated using the trapezoidal rule.

Clearance rates for glucose were calculated between $\mathrm{t}=10 \mathrm{~min}$ and $\mathrm{t}=60 \mathrm{~min}$ of the IVGTT by applying a one compartment monoexponential model with nonzero asymptote, such that: glucose $=\left(A_{o}-A_{\text {asym }}\right)$ $\times \mathrm{e}^{-\mathrm{k} t}+\mathrm{A}_{\text {asym }}$, with $t=$ time after the start of intravenous glucose administration; $\mathrm{k}=$ the elimination rate constant for glucose $(\% / \mathrm{min}) ; \mathrm{A}_{\mathrm{o}}=$ the extrapolated plasma glucose concentration assuming instantaneous mixing when $t=0 ; \mathrm{A}_{\text {asym }}=$ asymptotic plasma glucose concentration when time $\gg 0 \mathrm{~min}$ (Grünberg et al., 2011).

The apparent volume of distribution for glucose $\left(\mathrm{V}_{\mathrm{d}}\right)$ in $\mathrm{L}$ was calculated from the modeled curve for each IVGTT by dividing the amount of glucose infused (0.3 $\mathrm{g} / \mathrm{kg}$ of $\mathrm{BW}=1.67 \mathrm{mmol} / \mathrm{kg}$ of $\mathrm{BW}$ ) by the difference between $\mathrm{A}_{\mathrm{o}}$ and Baseline $\mathrm{Glucose}_{\mathrm{e}}$ concentration $(\mathrm{mmol} / \mathrm{L})$ using the equation: $\mathrm{V}_{\mathrm{d}}=[1.67 \times(\mathrm{BW}$ in $\mathrm{kg})] /\left(\mathrm{A}_{\mathrm{o}}-\right.$ Baseline $\left._{\text {Glucose }}\right)$. The apparent volume of distribution for glucose was calculated to provide an estimate for changes in the extracellular fluid volume because $V_{d}$ reflects the instantaneous apparent distribution volume for glucose.

\section{Analysis of the Dynamic Glucose and Insulin Response to an IVGTT}

The dynamic glucose and insulin response to an IVGTT was characterized by calculating the peak insulin concentration $\left(\mathrm{Peak}_{\text {Insulin }}\right)$, the time interval to Peak ${ }_{\text {Insulin, }}$ the increment in plasma insulin concentration for each IVGTT (Max Diff Insulin $_{\text {I }}$ ) by subtracting the

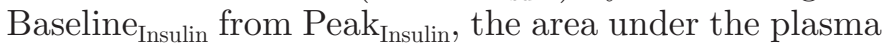
insulin concentration curve from 15 to 60 min after the start of the dextrose infusion $\left(\mathrm{AUC}_{\text {Insulin-60 }}\right)$, and the ratio of Baseline ${ }_{\text {Insulin }}$ to Baseline ${ }_{\text {Glucose }}$ (Baseline I/G ratio, Grünberg et al., 2011). The area under the concentration time curve for the insulin to glucose ratio $\left(\mathrm{AUC}_{\mathrm{I} / \mathrm{G}-60}\right)$ between 15 to $60 \mathrm{~min}$ after the start of the dextrose infusion was also calculated. Fifteen and 60 min were selected as the start and end points for AUC calculations related to insulin as this period represented the time interval where insulin clearance predominated over insulin release in healthy calves in this study reported here and elsewhere (MacPherson et al., 2016).

Insulin clearance rates were not calculated using a similar monoexponential decay equation as for plasma glucose concentrations because the plasma insulin concentrations in group A-BT did not follow an exponential decline. Instead, an insulin sensitivity index $\left(\mathrm{IS}_{\mathrm{i}}\right)$ was calculated using the following equation, which uses the change in the area under the plasma insulin concentration-time relationship $\left(\Delta \mathrm{AUC}_{\text {Insulin }}\right)$ for time $=0$ to $60 \mathrm{~min}$, such that $\mathrm{IS}_{\mathrm{i}}=\alpha \times \mathrm{k} /\left(\Delta \mathrm{AUC}_{\text {Insulin }} / \mathrm{T}\right)$, where $\alpha$ is a scaling factor $(\alpha=0.276), \mathrm{k}$ is the determined elimination rate constant for glucose $(\% / \mathrm{min})$, $\Delta \mathrm{AUC}_{\text {Insulin }}$ is the area under the insulin-time relationship (above basal) calculated using the trapezoid method, and $\mathrm{T}$ is the time interval from 0 to $60 \mathrm{~min}(=$ $60 \mathrm{~min}$ ) when $\mathrm{k}$ and $\Delta \mathrm{AUC}_{\text {Insulin }}$ are calculated (Tura et al., 2010; Pantophlet et al., 2016a). This index was considered to provide the primary measure of insulin 
sensitivity (tissue responsiveness to insulin) as the $\mathrm{IS}_{\mathrm{i}}$ relates glucose clearance to the prevailing plasma insulin concentration. Insulin sensitivity was also evaluated by calculating surrogate indices of insulin sensitivity from Baseline Glucose $_{\text {and }}$ Baseline Insulin $_{\text {including the re- }}$ ciprocal of baseline plasma insulin concentration (1/ insulin), the baseline glucose to insulin ratio (G/I; glucose in $\mathrm{mg} / \mathrm{dL}$ ), and the quantitative insulin sensitivity check index (QUICKI; Katz et al., 2000; Muniyappa et al., 2008). The QUICKI was calculated as follows (Katz et al., 2000; Muniyappa et al., 2008): QUICKI = 1/ $\left\{\log _{10}\left[\right.\right.$ Baseline $\left._{\text {Insulin }}(\mu \mathrm{IU} / \mathrm{mL})\right]+\log _{10}$ [Baseline $_{\text {Glucose }}$ $(\mathrm{mg} / \mathrm{dL})]\}$.

\section{Analysis of the Potassium-Insulin Relationship During an IVGTT}

Changes of plasma potassium concentration during the IVGTT and its association with changes of insulin concentrations were evaluated by determining the maximum decrement for plasma potassium concentration $\left(\operatorname{Max}_{\text {DiffK-60 }}\right)$ measured within 60 min after glucose infusion, and the ratio between the observed decrement of plasma potassium concentration relative to baseline and insulin concentrations (DiffK:I) at the time point of Peak ${ }_{\text {Insulin }}$. The net change in area under the plasma potassium concentration-time curve $\left(\mathrm{AUC}_{\text {DiffK-60 }}\right)$ from 0 to 60 min after the start of glucose infusion relative to baseline was calculated using the trapezoidal rule.

\section{Analysis of the Phosphorus-Insulin Relationship During an IVGTT}

The maximal decrease in plasma $\mathrm{P}_{\mathrm{i}}\left(\operatorname{Max}_{\text {DiffPi-60 }}\right)$ was calculated by subtracting the lowest $P_{i}$ measured within $60 \mathrm{~min}$ after glucose infusion from the Baseline $\mathrm{Pi}_{\mathrm{P}}$. Also similar to the plasma potassium concentrations, the ratio between the observed decrement of plasma $P_{i}$ relative to baseline and insulin concentrations $\left(\right.$ Diffe $\left._{\mathrm{i}}: \mathrm{I}\right)$ at the time point of Peak $\mathrm{Insulin}_{\text {was }}$ calculated.

The net change in the area under the plasma $\mathrm{Pi}$ concentration-time curve $\left(\mathrm{AUC}_{\mathrm{DiffP}-60}\right)$ from 0 to $60 \mathrm{~min}$ after the start of glucose infusion relative to baseline was calculated using the trapezoidal rule.

\section{Statistical Analysis}

Statistical analysis was conducted using SPSS (version 23, IBM, New York, NY), SAS (version 9.3, SAS Inst. Inc., Cary, NC), and GraphPad Prism (version 7.01, GraphPad software, La Jolla, CA). P-values $<0.05$ were considered to be statistically significant and a statistical trend was declared in case of $P$-values between 0.05 and 0.10 . A normal distribution of data was assessed by the Shapiro-Wilk test and visual inspection of QQ plots. If necessary, data were log-transformed to achieve a normal distribution of respective variables. Values of nonnormally distributed variables were backtransformed after statistical analysis to facilitate comparisons of values to previous studies and are reported as geometric mean and respective $95 \%$ confidence interval of the data. Values of untransformed variables are reported as mean \pm standard deviation.

A one-way ANOVA was used to determine group effects on assessed IVGTT parameters and a Bonferroni test was used as post-hoc test to compare variables between the 3 treatment groups (A-BT, NA, and C). A paired $t$-test was used to compare IVGTT variables in calves of group A before and after treatment. Group comparisons were not performed between calves of groups A-AT, NA, and C. Accordingly, scores of clinical parameters were compared using a nonparametric Kruskal-Wallis test (overall group effect), a MannWhitney U-test (comparisons between calves of groups A-BT, NA, and C), and a paired Wilcoxon test (comparisons between A-BT and A-AT).

\section{RESULTS}

\section{Basal Conditions}

Basal clinical and laboratory conditions of calves before conduction of IVGTT are presented in Tables 1 and 2. The age of group A calves did not differ from calves of group NA and C, but group NA calves were older than group C calves (Table 1). Calves of group A predominantly suffered from severe acidemia and presented with lower values for rectal temperature and higher scores for posture and behavior than calves of groups NA and C, respectively. The degree of enophthalmos and significantly higher plasma urea concentrations compared with calves of groups NA and C also indicated the presence of slight dehydration in group A calves.

Calves of group A had lower initial basal glucose concentrations than calves of group $\mathrm{C}$ and a hypoglycemic state was observed in most of the calves of group A after correction of metabolic acidosis. Basal insulin and $\mathrm{P}_{\mathrm{i}}$ concentrations differed in calves of group A before and after treatment as well as between calves of groups $\mathrm{NA}$ and C. Initial plasma potassium concentrations were similar in groups A-BT, NA, and C, but plasma potassium concentration decreased and a hypokalemic state was observed in calves of group A after treatment.

The mean increase in plasma volume and BW at the start of the second IVGTT $(3 \mathrm{~h}$ after the start of treatment) in group A calves was $19.0 \pm 7.9 \%$ and $0.5 \pm 0.8$ $\mathrm{kg}$, respectively. 
Table 1. Age, BW, and basal clinical values in 30 neonatal calves before administration of an intravenous glucose tolerance test ${ }^{1}$

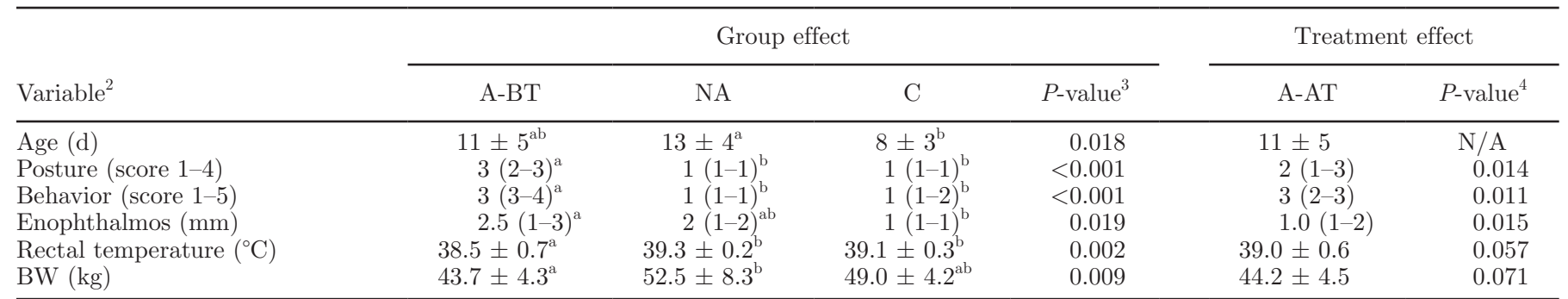

${ }_{\mathrm{a}, \mathrm{b}}$ Values within a row with different superscripts differ significantly (Bonferroni post hoc test or Mann-Whitney U-test; $P<0.05$ ).

${ }^{1}$ Each of 10 calves belonged to 1 of 3 of the following groups: acidemic diarrheic calves with an initial venous blood $\mathrm{pH}<7.20$ (group A) where an intravenous glucose tolerance test was performed before (group A-BT) and after treatment of acidemia (group A-AT), nonacidemic diarrheic calves with a measured venous blood $\mathrm{pH}>7.35$ (group NA), and healthy neonatal calves serving as a control group (group C).

${ }^{2}$ Data are reported as median and interquartile ranges or means \pm SD. Posture was scored as $1=$ standing securely, $2=$ insecurely, able to correct position; 3 = insecurely, unable to correct position; $4=$ unable to stand. Behavior was scored as $1=$ adequate reaction; very bright and alert; 2 = adequate reaction; $3=$ delayed reaction; $4=$ calf reacts only to painful stimuli; $5=$ no reaction to painful stimuli. Enophthalmos was quantified by measuring the distance $(\mathrm{mm})$ between the medial canthus and the eyeball.

${ }^{3} P$-values reflect the results of the overall ANOVA analysis or a nonparametric Kruskal-Wallis test.

${ }^{4} P$-values reflect the results of a pairwise comparisons of values of group A calves before and after treatment (paired $t$-test or nonparametric Wilcoxon test); N/A = not applicable.

Changes of plasma glucose and insulin concentrations during the IVGTT are displayed in Figure 1, and the observed decrement in plasma potassium and phosphorus concentrations are displayed in Figure 2. Results of the comparisons of analyzed IVGTT variables between treatment groups are presented in Table 3.

\section{Dynamic Glucose and Insulin Response to an IVGTT}

Differences were not identified for $\mathrm{AUC}_{\mathrm{Gluc}-60}$ between calves of groups A-BT, NA, and C, but $\mathrm{AUC}_{\text {Gluc-60 }}$ was lower in calves of group A after treatment when compared with values before treatment $(P=0.005)$. Glucose clearance rates were similar for calves in groups $\mathrm{A}-\mathrm{BT}$, NA, and $\mathrm{C}$, but a trend was observed toward higher clearance rates in calves of group A after treatment when compared with values before treatment $(P$ $=0.061)$.

The calculated apparent volume of distribution for glucose $\left(\mathrm{V}_{\mathrm{d}}\right)$ was similar $(P=1.0)$ in calves of group NA and $\mathrm{C}$, but was higher in those groups $(P \leq 0.002)$ when compared with calves in group A-BT. The calculated value for $\mathrm{V}_{\mathrm{d}}$ increased by $2.3 \pm 0.7 \mathrm{~L}$ in group A-AT calves, compared with group A-BT.

Marked differences in the slopes and amplitudes of the plasma insulin-concentration time curves were ob-

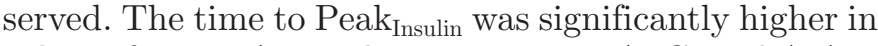
calves of group A-BT than in groups NA, C, and A-AT, respectively. Also, insulin concentrations remained relatively stable in calves of group A-BT between $\mathrm{t}=15$ min and 60 min, whereas a marked decrease of insulin concentrations was observed in calves of groups NA, $\mathrm{C}$, and A-AT during the same period of time (Figure 1). The observed values for $\mathrm{AUC}_{\text {Insulin-60 }}$ and $\mathrm{AUC}_{\mathrm{I} / \mathrm{G}-60}$ were significantly higher in calves of group A-BT than in calves of groups NA, and A-AT, but not when compared with calves of group C. A statistically significant difference for calculated values of IS $_{\mathrm{i}}$ was also found between groups A-BT, NA and A-AT, but not between $\mathrm{A}-\mathrm{BT}$ and $\mathrm{C}$, and not between NA and C.

The calculated values for surrogate indices of insulin sensitivity at baseline including 1/Insulin, G/I ratio, and QUICKI differed between calves of groups NA and $\mathrm{C}$ as well as between A-BT and A-AT.

\section{Plasma Potassium-Insulin Relationship}

Values for $\mathrm{AUC}_{\text {DiffK-60 }}$ in A-BT calves did not differ from those of groups NA, C, and A-AT, but a difference was found between calves of groups NA and C. No difference was observed in DiffK:I at the time point of

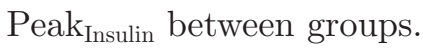

\section{Plasma Phosphorus-Insulin Relationship}

Only minimal changes for $\mathrm{P}_{\mathrm{i}}$ concentrations were observed during the IVGTT, with no difference between treatment groups.

\section{DISCUSSION}

The objective of the present study was to determine the magnitude of the effect of marked acidemia due to metabolic acidosis on the dynamic glucose and insulin response to an IVGTT in neonatal diarrheic calves. Central findings of this study indicate that the performed glucose challenge in profoundly acidemic diarrheic calves resulted in a comparable glucose clear- 
INSULIN RESPONSE TO INTRAVENOUS GLUCOSE

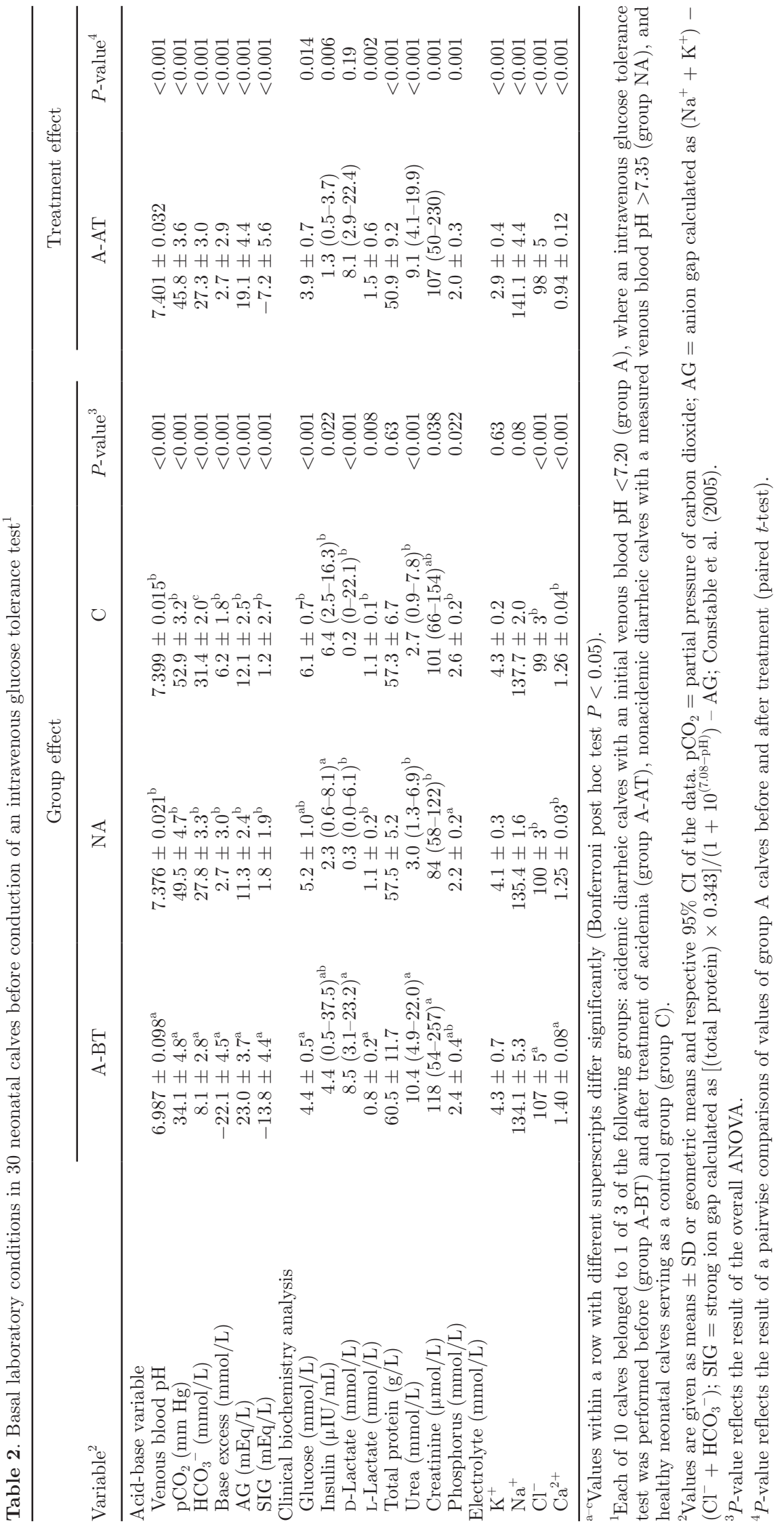


ance rate to that in nonacidemic diarrheic and healthy calves, but was associated with a markedly longer period of hyperinsulinemia and consequently a lower index of insulin sensitivity.

Previous studies have shown that even a very mild degree of acidemia is associated with the occurrence of insulin resistance in respect to glucose metabolism as observed in humans and dogs following ammoniumchloride-induced acidemia due to strong ion acidosis (Mackler et al., 1951; DeFronzo and Beckles, 1979), humans and rats with acidemia due to diabetic ketoacidosis (Walker et al., 1963; Cuthbert and Alberti,
1978), and in vitro studies on cultured adipocytes (Van Putten et al., 1985; Igarashi et al., 1993). In agreement with those studies, treatment with sodium bicarbonate increased insulin sensitivity and secretion in human patients with chronic kidney disease-related metabolic acidosis (Reaich et al., 1995; Mak, 1998), and lower serum bicarbonate concentrations and higher values for anion gap were found to be independently associated with an index of reduced insulin sensitivity in adult humans without diabetes or other chronic diseases (Farwell and Taylor, 2008). Acidemia-induced insulin resistance is caused at the cellular level by a reduced receptor bind-
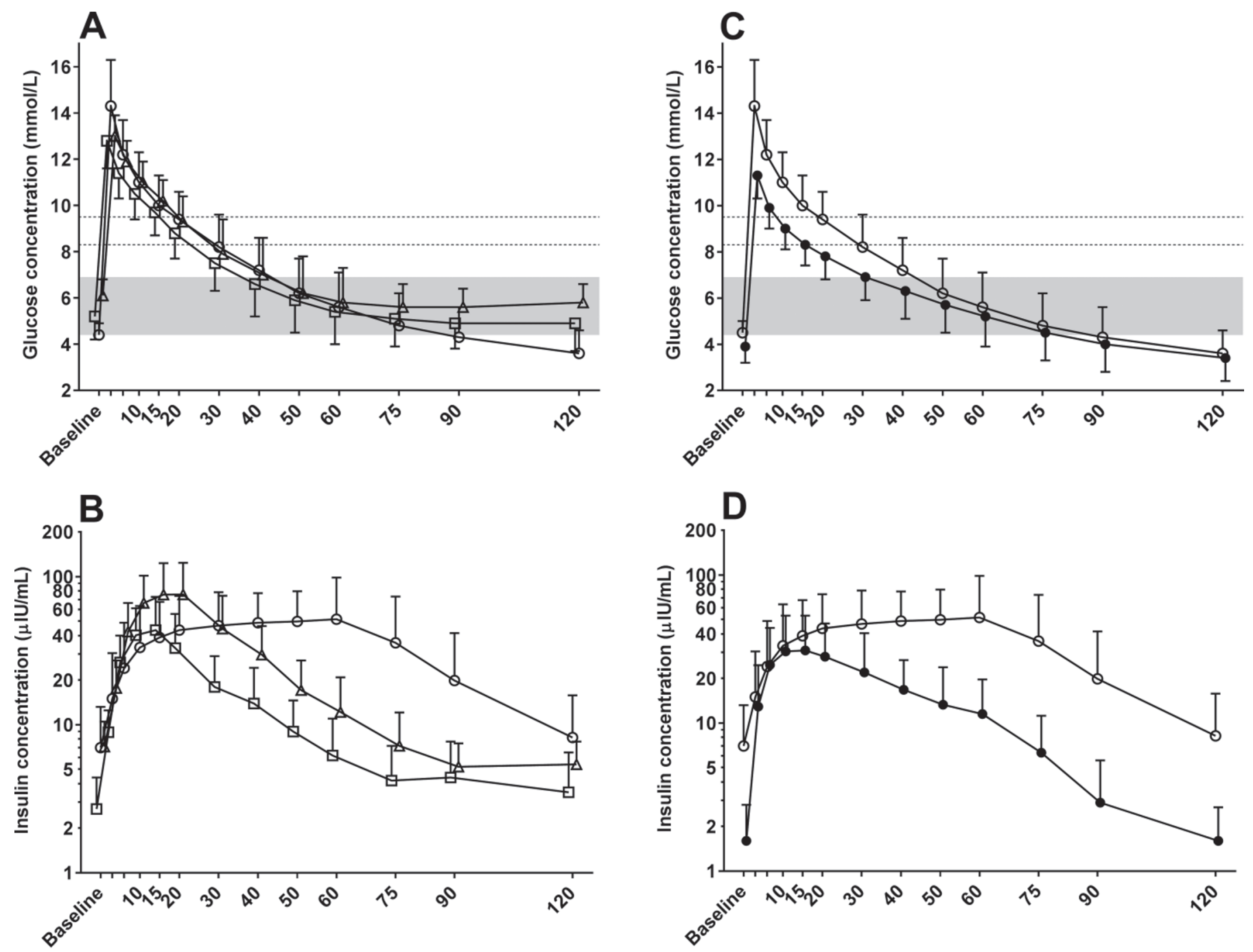

Time after start of IV glucose administration

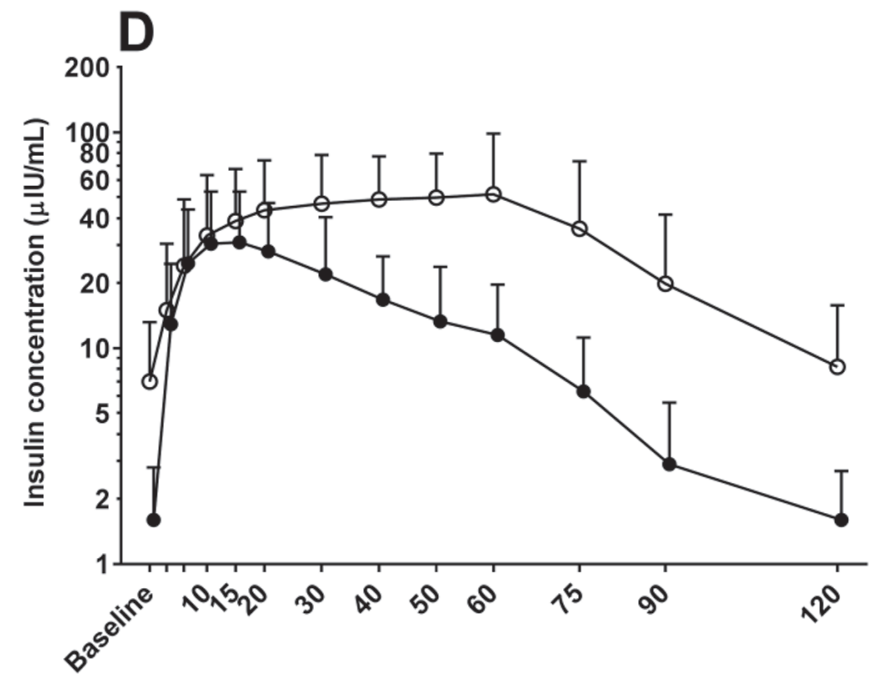

Time after start of IV glucose administration

Figure 1. Means $\pm \mathrm{SD}$ of plasma glucose (linear scale) and insulin concentrations (logarithmic scale) during an intravenous glucose tolerance test (IVGTT) in 30 neonatal calves. Values were slightly offset to improve readability. A and B: Changes of IVGTT variables in 10 acidemic diarrheic calves with venous blood $\mathrm{pH}<7.20$ (-O-), 10 nonacidemic diarrheic calves with a measured venous blood $\mathrm{pH}>7.35$ (- $\square$-), and 10 healthy neonatal calves $(-\Delta-)$. C and D: Changes of IVGTT variables of the 10 diarrheic calves with an initial venous blood $\mathrm{pH}<7.20$ after correction of acidemia (-) in comparison to values of the same calves before treatment (-o-). A and C: Gray-shaded areas indicate the reference range (4.4 to $6.9 \mathrm{mmol} / \mathrm{L}$ ) for plasma glucose concentrations in calves (Kraft and Dürr, 1995). Horizontal dashed lines indicate the anticipated range of values $(8.3$ to $9.5 \mathrm{mmol} / \mathrm{L}$ ) for renal threshold in calves (Scholz and Hoppe, 1987; Hostettler-Allen et al., 1994). 
ing affinity of insulin as well as by postbinding alterations (Van Putten et al., 1985; Igarashi et al., 1993). If insulin release is unaffected by acidemia, the net result of decreased plasma insulin clearance due to reduced insulin receptor binding would be sustained plasma insulin concentrations consistent with decreased entry of insulin into cells. In addition to an acidemia-induced alteration of the insulin-receptor interaction, a reduced insulin receptor concentration would represent another plausible explanation, as observed in studies on isolated adipocytes from ketoacidotic and ammonium-chloride acidotic rats (Whittaker et al., 1981, 1982). Interestingly, the number of insulin receptors in cell preparations from ketoacidotic rats was increased when the rats were treated with sodium bicarbonate, compared

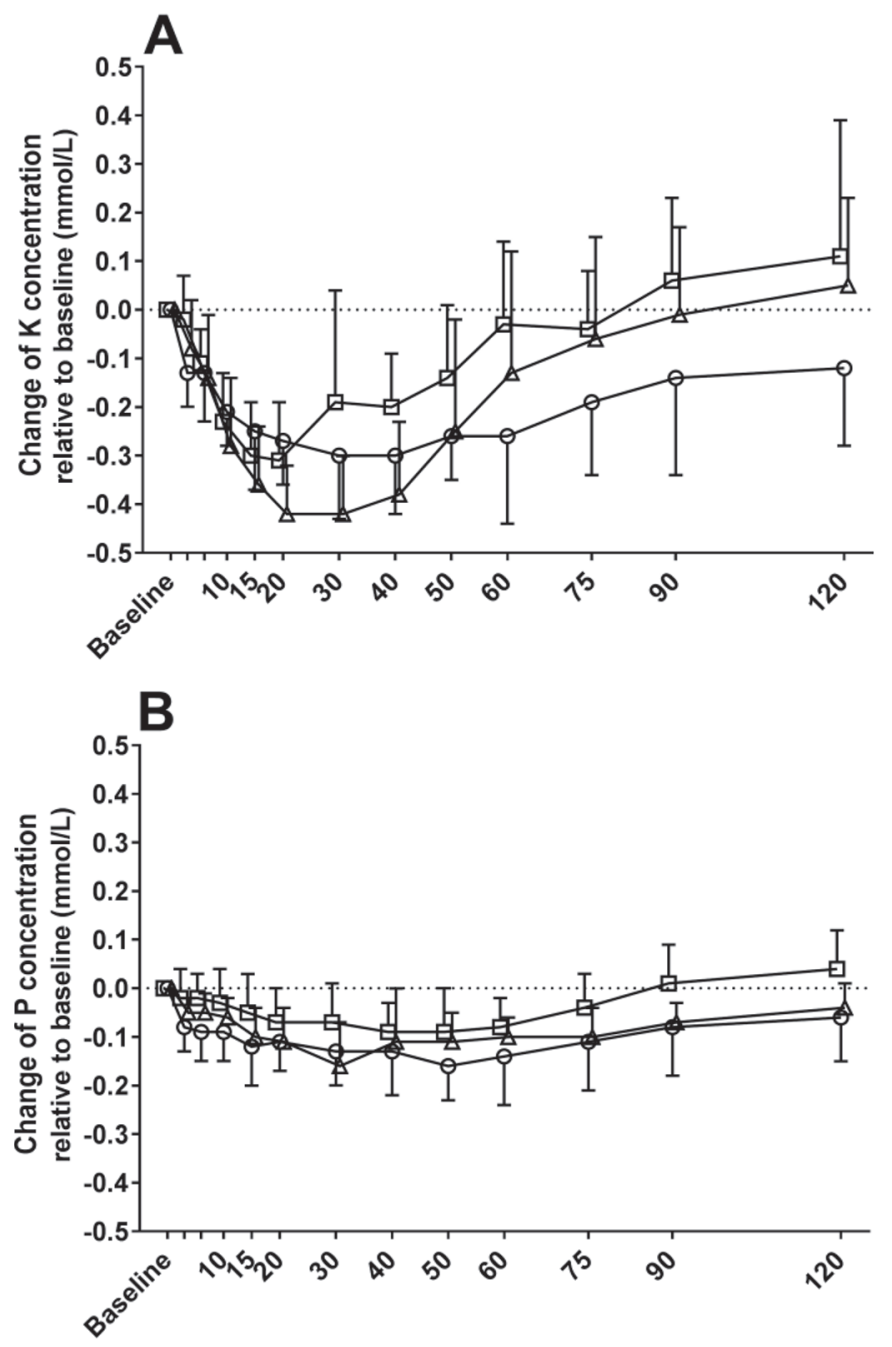

Time after start of IV glucose administration with untreated acidemic rats (Whittaker et al., 1982). Although not investigated in the study reported here, a bicarbonate-induced increase in the number of insulin receptors provides an explanation as to why correction of acidemia immediately increased insulin clearance in calves of the present study.

To the best of our knowledge the existence of an acidemia-induced insulin resistance has not been previously evaluated in neonatal diarrheic calves, but an impaired glucose-induced insulin response was reported in mildly acidemic cows after feeding an acidogenic diet (Bigner et al., 1996). This finding was, however, not confirmed in a study by Grünberg et al. (2011) where a mild but fully compensated metabolic acidosis in dairy cows did not affect insulin responsiveness or indices of

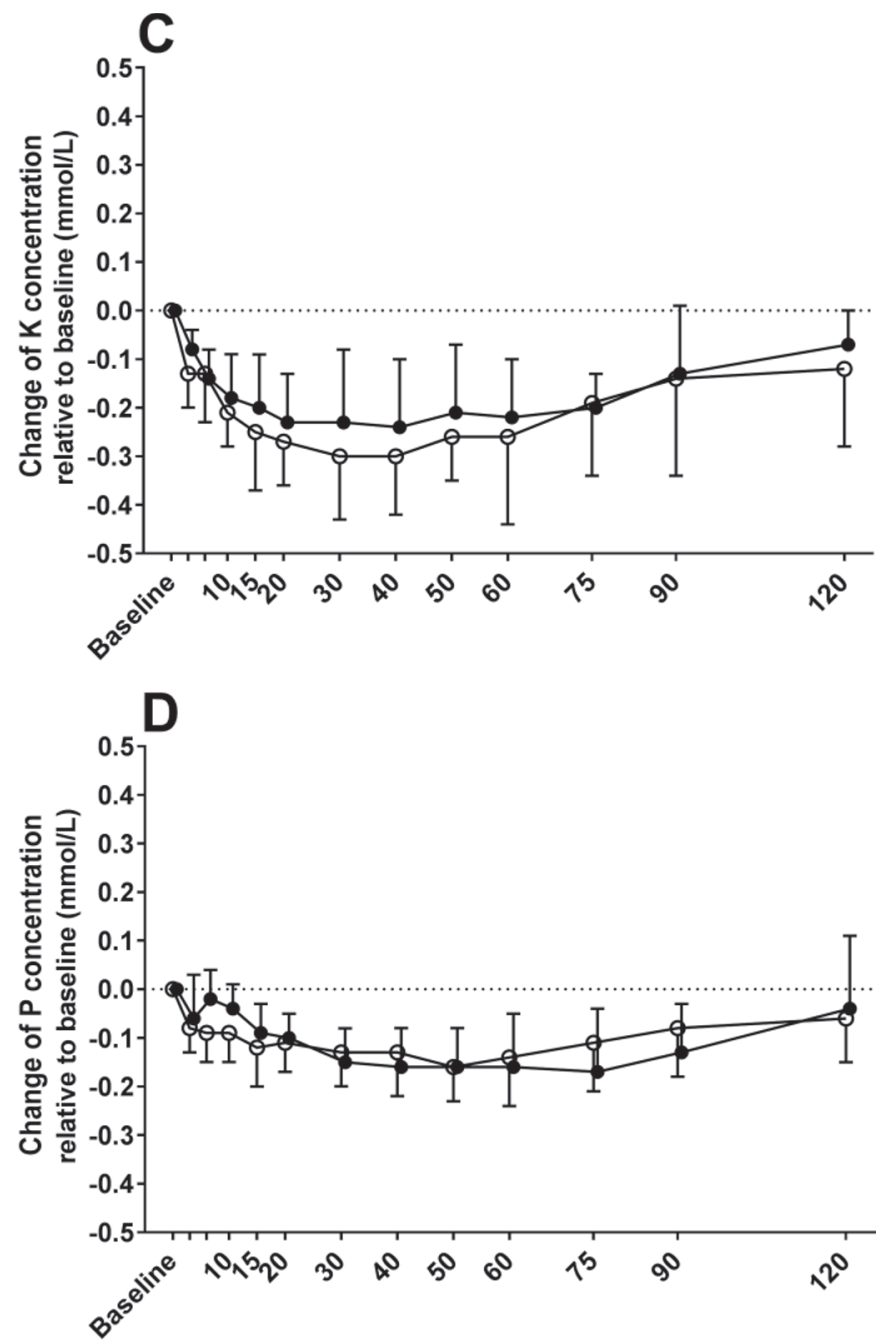

Time after start of IV glucose administration

Figure 2. Means $\pm \mathrm{SD}$ of changes of plasma potassium and phosphorus concentrations relative to baseline during an intravenous glucose tolerance test in 30 neonatal calves. A and B: Changes of variables in 10 acidemic diarrheic calves with venous blood pH $<7.20(-\bigcirc-)$, 10 nonacidemic diarrheic calves with a measured venous blood $\mathrm{pH}>7.35(-\square-)$, and 10 healthy neonatal calves $(-\Delta$-). Values were slightly offset to improve readability. C and D: Changes of variables of the 10 diarrheic calves with an initial venous blood $\mathrm{pH}<7.20$ after correction of acidemia (-) in comparison to values of the same calves before treatment (-O-). 


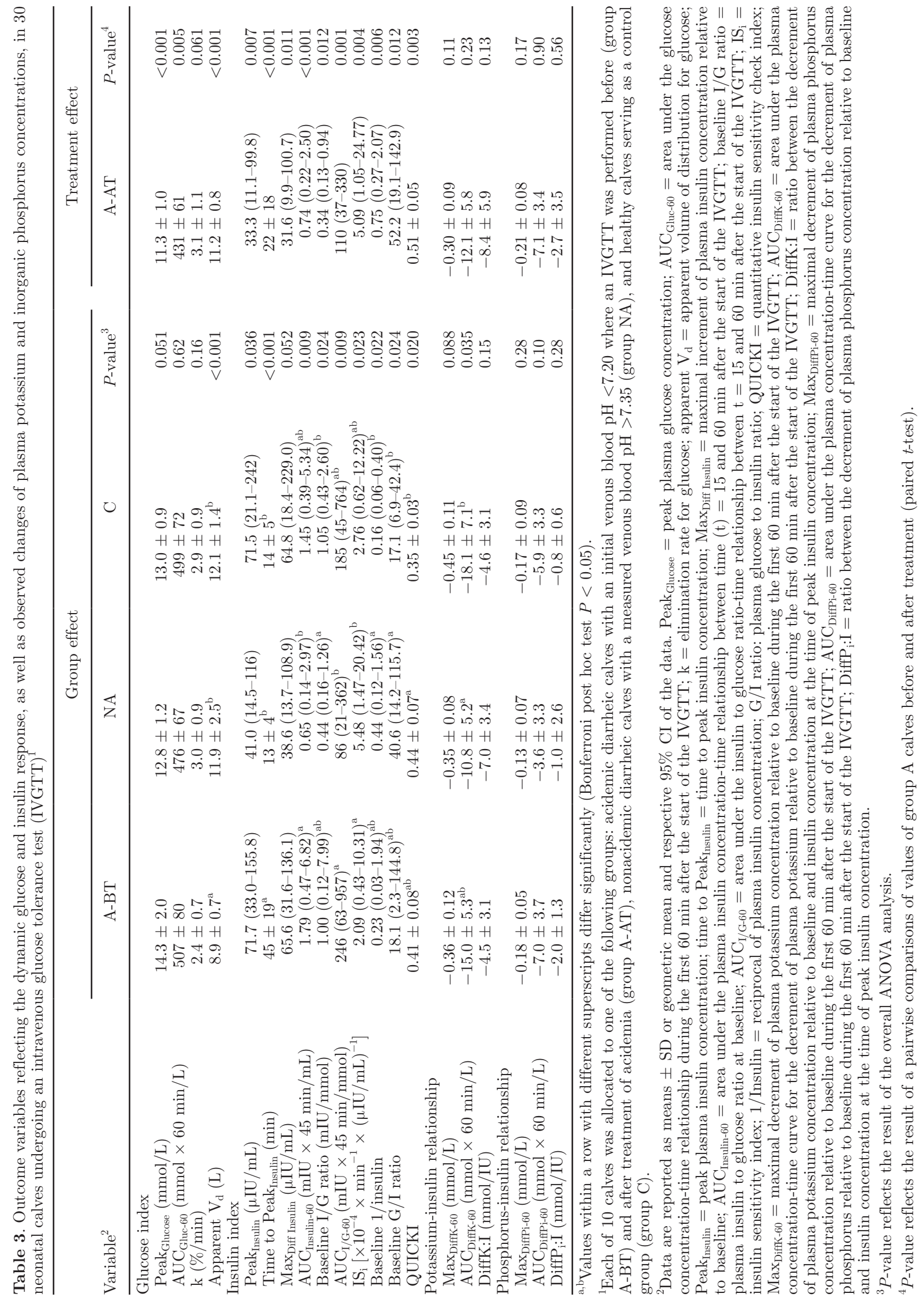


insulin sensitivity during an IVGTT. Moreover, our finding in the study reported here of similar values for Peak $_{\text {Insulin }}$ in groups A-BT, NA, and C suggest that insulin secretion is not impaired in severely acidemic calves.

Nonsignificant differences for $\mathrm{AUC}_{\mathrm{Gluc}-60}$ and the observed glucose clearance rates additionally indicated that acidemic diarrheic calves were similar effective in controlling glycemia than calves of groups NA and C. The observed glucose clearance rates in the present study were comparable to those of previously reported values for neonatal Belgian Blue calves but higher than previously reported values for neonatal Holstein calves (Bossaert et al., 2009) or periparturient Holstein cows (Mann et al., 2016), although methodical aspects need to be considered when comparing glucose clearance between studies.

The numerically lower values for $\mathrm{AUC}_{\mathrm{Gluc}-60}$ as well

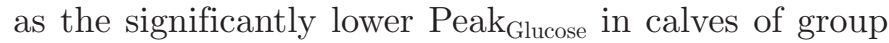
A-AT compared with A-BT in calves of the present can be at least partly explained by an increase of plasma volume and consequently an increased distribution space for glucose. The calculated values for $\mathrm{V}_{\mathrm{d}}$ increased by a mean of $2.3 \mathrm{~L}$, which is consistent with an infusion volume of $2.5 \mathrm{~L}$ in those calves, whereas BW only increased by $0.5 \mathrm{~kg}$. The latter suggests that those calves urinated or defecated over the 2.5-h study period with a net loss of $2.0 \mathrm{~kg}$.

Of importance is our finding that values for AU$\mathrm{C}_{\text {Insulin-60 }}$ and $\mathrm{AUC}_{\mathrm{I} / \mathrm{G}-60}$ were significantly higher and values for $\mathrm{IS}_{\mathrm{i}}$ were significantly lower in acidemic calves than in group NA and in the same calves after treatment with sodium bicarbonate. Also, a remarkable finding was that the plasma insulin concentration remained unchanged between $\mathrm{t}=15 \mathrm{~min}$ and $\mathrm{t}=60 \mathrm{~min}$ after glucose injections, whereas a marked elimination of insulin was observed in all other groups. These findings suggest that acidemic calves are insulin resistant in that acidemic calves required a prolonged period of hyperinsulinemia for controlling the induced glucose challenge. This conclusion is, however, not supported by values of surrogate indices, which were calculated from baseline plasma insulin and glucose concentration and were not found to be significantly different between calves of group A-BT and calves of groups NA and C. Surrogate indices are widely used in human medicine as indirect and reliable measures of insulin sensitivity/ resistance and have subsequently been copied for use in veterinary medicine although those measures require validation for use in cattle (Muniyappa et al., 2008; De Koster and Opsomer, 2013). Also, in the present study the results of these surrogate indices should be interpreted cautiously as different levels of glycemia were evident at baseline, which were not reflected by insulin sensitivity. Hypoglycemia was observed in calves of group A at baseline of the IVGTT before and after treatment with sodium bicarbonate, and it is therefore likely that the glucose to insulin ratio was influenced in those animals by hypoinsulinemia as well as by counter-regulatory mechanisms in an attempt to increase plasma glucose concentrations. Nevertheless, the observed significant differences for surrogate indices together with numerically (but not significantly) higher values for $\mathrm{AUC}_{\text {Insulin-60 }}$ and $\mathrm{AUC}_{\mathrm{I} / \mathrm{G}-60}$ as well as numerically lower values for $\mathrm{IS}_{\mathrm{i}}$ in calves of groups $\mathrm{C}$ compared with calves of group NA requires explanation. Previous studies have shown that the plane of nutrition affects insulin sensitivity in milk-fed dairy calves (HostettlerAllen et al., 1994; Hugi et al., 1997; Bach et al., 2013). Although those observations are based on experiments in older calves and on high-intensity feeding programs performed over a period of several weeks, it is conceivable that a lower intake of milk in diarrheic calves compared with healthy control calves might have had an effect on insulin sensitivity. This would also mean that the results of the comparison of $\mathrm{AUC}_{\text {Insulin-60 }}, \mathrm{AUC}_{\mathrm{I} / \mathrm{G}-60}$, and $\mathrm{IS}_{\mathrm{i}}$ between calves of groups A-BT and $\mathrm{C}$ should be interpreted cautiously in as much that a higher level of insulin sensitivity due to malnutrition could have been evident in calves of group A (which is supported by the observed $\mathrm{AUC}_{\text {Insulin-60 }}$ and $\mathrm{AUC}_{\mathrm{I} / \mathrm{G}-60}$ after treatment) but was, however, masked during an acidemic state and therefore resulted in a similar insulin response than in calves of group C. Remarkably, values for $\mathrm{IS}_{\mathrm{i}}$ in group $\mathrm{C}$ calves were much lower than previously published values for neonatal Holstein Frisian and Jersey calves (Stanley et al., 2002) and only slightly higher than reported values for older milk fed veal Holstein calves (Pantophlet et al., 2016b), which might be related to methodical differences. In addition to the effect of correction of metabolic acidosis, nutritional aspects might also provide an explanation for the observed differences of IVGTT parameters between calves of groups A-BT and A-AT as there was a time period of at least $5 \mathrm{~h}$ without feed intake before start of the second IVGTT. This was likely reflected by the observed baseline glucose and insulin concentrations in those calves after treatment.

Aside from nutritional aspects a different level of stress susceptibility might also have affected the outcome of our analyses. Although stress was reduced as much as possible and calves appeared generally quiet during the IVGTT, it is still possible that healthy control calves were more susceptible to unavoidable stressors such as new environmental conditions or catheterization as it was the case in ill calves suffering from diarrhea and a certain level of depression. Another issue is a high interindividual variability of IVGTT parameters that was 
especially observed in calves of group A. This might be related to the presence of concurrent clinical and metabolic conditions in some calves. Although we tried to minimize the effect of concurrent problems as much as possible by definition of exclusion criteria, the effect of hypoglycemia, hypothermia, or variable degrees of dehydration could not be completely prevented as they are frequently associated with the presence of severe acidemia due to metabolic acidosis in diarrheic calves.

No statistically significant difference was found in the present study for $\mathrm{AUC}_{\text {DiffK-60 }}$ between calves of group A-BT and calves of groups NA, C, and A-AT. Also the calculated values of DiffK:I at the time of $\mathrm{Peak}_{\text {Insulin }}$ were not different between treatment groups. Collectively, it appears that the insulin-induced potassium response was not impaired by an acidemic state.

Insulin induces a cellular uptake of glucose, potassium, and phosphorus that is achieved by different mechanisms at the cellular level. Insulin-stimulated glucose uptake is mediated by the facilitative glucose transporter GLUT4, which is translocated to the plasma membrane in insulin-sensitive tissues (Gumà et al., 1995; Duhlmeier et al., 2005). Insulin-stimulated potassium uptake is mediated by activation of the $\mathrm{Na}^{+} / \mathrm{K}^{+}$-ATPase, which was reported to be further enhanced by an increased intracellular sodium flux (Rosic et al., 1985; Hundal et al., 1992). Insulin-stimulated phosphorus uptake is mediated by insulin-dependent upregulation of $\mathrm{Na} / \mathrm{P}_{\mathrm{i}}$ co-transporter gene expression (Li et al., 1996). Only minimal changes of plasma phosphorus concentrations were observed during the IVGTT in the present study, which is in contrast to studies in periparturient dairy cows, where significant decreases of plasma phosphorus concentrations after bolus injections of glucose solutions has been reported (Grünberg et al., 2006, 2011). Several potential mechanisms might have contributed to this finding. The renal phosphorus threshold in ruminants is $7.0 \mathrm{mg} / \mathrm{dL}(2.3$ mmol/L; Symonds and Manston, 1974) and neonatal calves typically excrete $40 \%$ of daily phosphorus intake in urine, compared with a very low percentage in adult ruminants (Boehncke and Tiews, 1972). Also calves have much more available skeletal phosphorus, which is different from the situation in adult ruminants (Horst, 1986). Therefore, intracellular phosphorus translocation in response to insulin release might have happened in calves of the present study, but increased mobilization of phosphorus from bone as well as increased renal reabsorption most likely occurred at a fast enough rate to keep plasma phosphorus concentrations stable. Increased renal reabsorption might have been enhanced by hyperinsulinemia, which was reported to result in increased tubular phosphorus reabsorption in dogs, thereby reducing phosphorus losses into urine (DeFron- zo et al., 1976; Hammerman et al., 1984). A potential explanation for a marked phosphorus-lowering effect of hyperinsulinemia in response to dextrose infusions in dairy cows (Grünberg et al., 2006, 2011) is that adult ruminants are not able to decrease urinary phosphorus excretion and have very little rapidly mobilizable phosphorus from bone. It would therefore appear that the insulin-phosphorus relationship in neonatal calves is not a good method to dissect out the mechanisms of insulin dysfunction in acidemia.

Interestingly, previous studies in humans have shown that the insulin-stimulated cellular uptake of glucose, potassium, or phosphorus are not coupled and are independently regulated from each other. Selective resistance mechanisms exist such that impaired glucose disposal (as in diabetic patients) does not necessarily affect potassium uptake and vice versa (Cohen et al., 1991; Nguyen et al., 2011). An experimental study in rats has shown that even a short-term potassium deprivation due to administration of a potassium-deficient diet (which only caused a 9\% reduction of plasma potassium concentration) resulted in an $80 \%$ reduction in insulin-stimulated cellular potassium uptake, whereas glucose disposal rates were not affected (Choi et al., 2001). The occurrence of this selective insulin resistance was considered as a homeostatic mechanism to maintain extracellular potassium concentration after ingestion of meals that are rich in carbohydrates but low in potassium (Youn and McDonough, 2009). A similar situation might have also been evident in the present study as calves had to handle a potassium-free glucose challenge. Furthermore, all calves in the present study were nonhyperkalemic, and marked hypokalemia was even evident in calves of group A after correction of acidemia. This finding can be interpreted as a marked depletion of body potassium stores as the plasma potassium concentration is considered to more accurately reflect body potassium stores when blood $\mathrm{pH}$ values are within the reference range (Burnell and Scribner, 1957). Consequently, a selective insulin resistance for cellular potassium uptake (not caused by acidemia) might explain the observed Max $_{\text {DiffK-60 }}$ values in the present study, which were generally low and would be unlikely to induce a clinically relevant treatment effect in diarrheic calves suffering from hyperkalemia. The therapeutic utility of endogenous insulin release in response to administration of a glucose containing infusion solutions should therefore be assessed in diarrheic calves with hyperkalemia.

\section{CONCLUSIONS}

A prolonged period of hyperinsulinemia as well as an increased insulin to glucose ratio during an IVGTT is 
suggestive for the existence of insulin resistance in respect to glucose metabolism in severely acidemic calves with diarrhea. How much those findings are relevant to intravenous fluid therapy in those animals needs to be assessed in future investigations. However, the finding that acidemic calves were similarly effective in controlling the induced glucose challenge suggests that acidemic calves could be treated with glucose if necessary. Also, our finding that acidemic calves had a similar decline of plasma potassium concentrations per unit insulin than healthy control calves or nonacidemic calves with diarrhea indicates that glucose-containing infusion solutions may have therapeutic utility in the treatment of acidemic calves with hyperkalemia. From a clinical relevance viewpoint, findings of this study again emphasize the importance of correcting acidemia due to metabolic acidosis in the treatment of neonatal diarrheic calves.

\section{ACKNOWLEDGMENTS}

This study was supported by a research grant (TR 1321/1-1) of the German Research Foundation (Deutsche Forschungsgemeinschaft, Bonn, Germany). The authors thank Stefan Nüske (Teaching and Research Farm of LMU Munich) for providing us with calves and Sandra Kirsch, Ingrid Hartmann, and Monika Altmann (Clinic for Ruminants, LMU Munich) for technical assistance.

\section{REFERENCES}

Abuelo, A., J. De Koster, J. Hernandez, G. Opsomer, L. Grufman, and C. Castillo. 2012. Quantifying bovine insulin: Conversion of units. Vet. Clin. Pathol. 41:308-310.

Bach, A., L. Domingo, C. Montoro, and M. Terre. 2013. Short communication: insulin responsiveness is affected by the level of milk replacer offered to young calves. J. Dairy Sci. 96:4634-4637.

Berchtold, J. 2009. Treatment of calf diarrhea: Intravenous fluid therapy. Vet. Clin. North Am. Food Anim. Pract. 25:73-99.

Bia, M. J., and R. A. DeFronzo. 1981. Extrarenal potassium homeostasis. Am. J. Physiol. 240:F257-F268.

Bigner, D. R., J. P. Goff, M. A. Faust, J. L. Burton, H. D. Tyler, and R. L. Horst. 1996. Acidosis effects on insulin response during glucose tolerance tests in Jersey cows. J. Dairy Sci. 79:2182-2188.

Boehncke, E., and J. Tiews. 1972. Untersuchungen über die renale Phosphatausscheidung des Rindes. Z. Tierphysiol. Tierernährung u. Futtermittelkde 29:34.

Bossaert, P., J. L. Leroy, S. De Campeneere, S. De Vliegher, and G. Opsomer. 2009. Differences in the glucose-induced insulin response and the peripheral insulin responsiveness between neonatal calves of the Belgian Blue, Holstein-Friesian, and East Flemish breeds. J. Dairy Sci. 92:4404-4411.

Burnell, J. M., and B. H. Scribner. 1957. Serum potassium concentration as a guide to potassium need. J. Am. Med. Assoc. 164:959962.

Choi, C. S., C. B. Thompson, P. K. Leong, A. A. McDonough, and J. H. Youn. 2001. Short-term $\mathrm{K}^{+}$deprivation provokes insulin resistance of cellular $\mathrm{K}^{+}$uptake revealed with the $\mathrm{K}^{+}$clamp. Am. J. Physiol. Renal Physiol. 280:F95-F102.
CLSI (Clinical and Laboratory Standards Institute). 2009. Blood gas and $\mathrm{pH}$ analysis and related measurements. CLSI document C46A2. Approved guideline. 2nd ed. Clinical and Laboratory Standards Institute, Wayne, PA.

Cohen, P., N. Barzilai, A. Lerman, H. Harel, P. Szylman, and E. Karnieli. 1991. Insulin effects on glucose and potassium metabolism in vivo: Evidence for selective insulin resistance in humans. J. Clin. Endocrinol. Metab. 73:564-568.

Constable, P. D. 2002. The treatment of the diarrheic calf: An update. Pages 132-143 in Keynote Lectures XXII World Buiatrics Congress, Hannover, Germany. Klinik für Rinderkrankheiten, Tierärztliche Hochschule Hannover, Hannover, Germany.

Constable, P. D., and W. Grünberg. 2013. Hyperkalemia in diarrheic calves: Implications for diagnosis and treatment. Vet. J. 195:271272 .

Constable, P. D., H. R. Stämpfli, H. Navetat, J. Berchtold, and F. Schelcher. 2005. Use of a quantitative strong ion approach to determine the mechanism for acid-base abnormalities in sick calves with or without diarrhea. J. Vet. Intern. Med. 19:581-589.

Constable, P. D., P. G. Walker, D. E. Morin, and J. H. Foreman. 1998 Clinical and laboratory assessment of hydration status of neonatal calves with diarrhea. J. Am. Vet. Med. Assoc. 212:991-996.

Coskun, A., I. Sen, H. Guzelbektes, M. Ok, K. Turgut, and S. Canikli. 2010. Comparison of the effects of intravenous administration of isotonic and hypertonic sodium bicarbonate solutions on venous acid-base status in dehydrated calves with strong ion acidosis. J. Am. Vet. Med. Assoc. 236:1098-1103.

Cox, M., R. H. Sterns, and I. Singer. 1978. The defense against hyperkalemia: The roles of insulin and aldosterone. N. Engl. J. Med. 299:525-532.

Cuthbert, C., and K. G. Alberti. 1978. Acidemia and insulin resistance in the diabetic ketoacidotic rat. Metabolism 27(Suppl. 2):19031916.

De Koster, J. D., and G. Opsomer. 2013. Insulin resistance in dairy cows. Vet. Clin. North Am. Food Anim. Pract. 29:299-322.

DeFronzo, R. A., and A. D. Beckles. 1979. Glucose intolerance following chronic metabolic acidosis in man. Am. J. Physiol. 236:E328E334.

DeFronzo, R. A., M. Goldberg, and Z. S. Agus. 1976. The effects of glucose and insulin on renal electrolyte transport. J. Clin. Invest. 58:83-90.

Duhlmeier, R., A. Hacker, A. Widdel, W. von Engelhardt, and H. P. Sallmann. 2005. Mechanisms of insulin-dependent glucose transport into porcine and bovine skeletal muscle. Am. J. Physiol. Regul. Integr. Comp. Physiol. 289:R187-R197.

Farwell, W. R., and E. N. Taylor. 2008. Serum bicarbonate, anion gap and insulin resistance in the National Health and Nutrition Examination Survey. Diabet. Med. 25:798-804.

Grünberg, W., S. S. Donkin, and P. D. Constable. 2011. Periparturient effects of feeding a low dietary cation-anion difference diet on acidbase, calcium, and phosphorus homeostasis and on intravenous glucose tolerance test in high-producing dairy cows. J. Dairy Sci. 94:727-745.

Grünberg, W., D. E. Morin, J. K. Drackley, and P. D. Constable. 2006. Effect of rapid intravenous administration of $50 \%$ dextrose solution on phosphorus homeostasis in postparturient dairy cows. J. Vet. Intern. Med. 20:1471-1478.

Gumà, A., J. R. Zierath, H. Wallberg-Henriksson, and A. Klip. 1995. Insulin induces translocation of GLUT-4 glucose transporters in human skeletal muscle. Am. J. Physiol. 268:E613-E622.

Hammerman, M. R., S. Rogers, V. A. Hansen, and J. R. Gavin. 1984 Insulin stimulates Pi transport in brush border vesicles from proximal tubular segments. Am. J. Physiol. 247:E616-E624.

Horst, R. L. 1986. Regulation of calcium and phosphorus homeostasis in the dairy cow. J. Dairy Sci. 69:604-616.

Hostettler-Allen, R. L., L. Tappy, and J. W. Blum. 1994. Insulin resistance, hyperglycemia, and glucosuria in intensively milk-fed calves. J. Anim. Sci. 72:160-173.

Hugi, D., R. M. Bruckmaier, and J. W. Blum. 1997. Insulin resistance, hyperglycemia, glucosuria, and galactosuria in intensively milk-fed 
calves: Dependency on age and effects of high lactose intake. J. Anim. Sci. 75:469-482.

Hundal, H. S., A. Marette, Y. Mitsumoto, T. Ramlal, R. Blostein, and A. Klip. 1992. Insulin induces translocation of the alpha 2 and beta 1 subunits of the $\mathrm{Na}^{+} / \mathrm{K}^{+}$-ATPase from intracellular compartments to the plasma membrane in mammalian skeletal muscle. J. Biol. Chem. 267:5040-5043.

Igarashi, M., K. Yamatani, N. Fukase, M. Daimon, H. Ohnuma, A. Ogawa, M. Tominaga, and H. Sasaki. 1993. Effect of acidosis on insulin binding and glucose uptake in isolated rat adipocytes. Tohoku J. Exp. Med. 169:205-213.

Katz, A., S. S. Nambi, K. Mather, A. D. Baron, D. A. Follmann, G. Sullivan, and M. J. Quon. 2000. Quantitative insulin sensitivity check index: A simple, accurate method for assessing insulin sensitivity in humans. J. Clin. Endocrinol. Metab. 85:2402-2410.

Knochel, J. P. 1977. The pathophysiology and clinical characteristics of severe hypophosphatemia. Arch. Intern. Med. 137:203-220.

Koch, A., and M. Kaske. 2008. Clinical efficacy of intravenous hypertonic saline solution or hypertonic bicarbonate solution in the treatment of inappetent calves with neonatal diarrhea. J. Vet. Intern. Med. 22:202-211.

Kraft, W., and U. Dürr. 1995. Klinische Labordiagnostik in der Tiermedizin. 3rd ed. Schattauer Verlag, Stuttgart.

Lewis, L. D., and R. W. Phillips. 1973. Diarrheic induced changes in intracellular and extracellular ion concentrations in neonatal calves. Ann. Rech. Vétér. 4:99-111.

Li, H., P. Ren, M. Onwochei, R. J. Ruch, and Z. Xie. 1996. Regulation of rat $\mathrm{Na}^{+} / \mathrm{Pi}$ cotransporter-1 gene expression: The roles of glucose and insulin. Am. J. Physiol. 271:E1021-E1028.

Lorenz, I. 2004. Influence of D-lactate on metabolic acidosis and on prognosis in neonatal calves with diarrhoea. J. Vet. Med. A Physiol. Pathol. Clin. Med. 51:425-428.

Lorenz, I., and F. Trefz. 2016. Metabolic disturbances in neonatal calves with diarrhoea-Clinical signs and treatment. Pages 85-88 in Proceedings of the 29th World Buiatrics Congress, Dublin, Ireland. Veterinary Ireland, Dublin, Ireland.

Lorenz, I., and S. Vogt. 2006. Investigations on the association of D-lactate blood concentrations with the outcome of therapy of acidosis, and with posture and demeanour in young calves with diarrhoea. J. Vet. Med. A Physiol. Pathol. Clin. Med. 53:490-494.

Mackler, B., H. Lichtenstein, and G. M. Guest. 1951. Effects of ammonium chloride acidosis on the action of insulin in dogs. Am. J. Physiol. 166:191-198.

MacPherson, J. A., H. Berends, L. N. Leal, J. P. Cant, J. Martin-Tereso, and M. A. Steele. 2016. Effect of plane of milk replacer intake and age on glucose and insulin kinetics and abomasal emptying in female Holstein Friesian dairy calves fed twice daily. J. Dairy Sci. 99:8007-8017.

Mak, R. H. 1998. Effect of metabolic acidosis on insulin action and secretion in uremia. Kidney Int. 54:603-607.

Mann, S., F. A. Leal Yepes, M. Duplessis, J. J. Wakshlag, T. R. Overton, B. P. Cummings, and D. V. Nydam. 2016. Dry period plane of energy: Effects on glucose tolerance in transition dairy cows. J. Dairy Sci. 99:701-717.

Muniyappa, R., S. Lee, H. Chen, and M. J. Quon. 2008. Current approaches for assessing insulin sensitivity and resistance in vivo: Advantages, limitations, and appropriate usage. Am. J. Physiol. Endocrinol. Metab. 294:E15-E26.

Nguyen, T. Q., N. M. Maalouf, K. Sakhaee, and O. W. Moe. 2011. Comparison of insulin action on glucose versus potassium uptake in humans. Clin. J. Am. Soc. Nephrol. 6:1533-1539.

Niethammer, F. M. 2007. Untersuchungen zur Dehydratation bei Kälbern mit akuter Diarrhoe unter Berücksichtigung ausgewählter klinischer und labordiagnostischer Parameter. Doctoral Thesis. Veterinary Faculty, Ludwig-Maximilians-Universität, Munich, Germany.

Pantophlet, A. J., M. S. Gilbert, J. J. van den Borne, W. J. Gerrits, M. G. Priebe, and R. J. Vonk. 2016a. Insulin sensitivity in calves decreases substantially during the first 3 months of life and is unaffected by weaning or fructo-oligosaccharide supplementation. J. Dairy Sci. 99:7602-7611.
Pantophlet, A. J., M. S. Gilbert, J. J. van den Borne, W. J. Gerrits, H. Roelofsen, M. G. Priebe, and R. J. Vonk. 2016b. Lactose in milk replacer can partly be replaced by glucose, fructose, or glycerol without affecting insulin sensitivity in veal calves. J. Dairy Sci. 99:3072-3080

Reaich, D., K. A. Graham, S. M. Channon, C. Hetherington, C. M. Scrimgeour, R. Wilkinson, and T. H. Goodship. 1995. Insulinmediated changes in $\mathrm{PD}$ and glucose uptake after correction of acidosis in humans with CRF. Am. J. Physiol. 268:E121-E126.

Rosic, N. K., M. L. Standaert, and R. J. Pollet. 1985. The mechanism of insulin stimulation of $\left(\mathrm{Na}^{+}, \mathrm{K}^{+}\right)$-ATPase transport activity in muscle. J. Biol. Chem. 260:6206-6212.

Scholz, H., and S. Hoppe. 1987. Renale Glukoseverluste nach intravenöser Glukoseinfusion beim Kalb. Dtsch. tieräztl. Wschr. 94:473-476.

Stanley, C. C., C. C. Williams, B. F. Jenny, J. M. Fernandez, H. G. Bateman, W. A. Nipper, J. C. Lovejoy, D. T. Gantt, and G. E. Goodier. 2002. Effects of feeding milk replacer once versus twice daily on glucose metabolism in Holstein and Jersey calves. J. Dairy Sci. 85:2335-2343.

Sweeney, R. W. 1999. Treatment of potassium balance disorders. Vet. Clin. North Am. Food Anim. Pract. 15:609-617.

Symonds, H. W., and R. Manston. 1974. The response of the bovine kidney to increasing plasma inorganic phosphorous concentrations. Res. Vet. Sci. 16:131-133.

Thomas, L. J. 1972. Algorithms for selected blood acid-base and blood gas calculations. J. Appl. Physiol. 33:154-158.

Trefz, F. M., P. D. Constable, and I. Lorenz. 2015a. Quantitative physicochemical analysis of acid-base balance and clinical utility of anion gap and strong ion gap in 806 neonatal calves with diarrhea. J. Vet. Intern. Med. 29:678-687.

Trefz, F. M., P. D. Constable, C. Sauter-Louis, A. Lorch, G. KnubbenSchweizer, and I. Lorenz. 2013a. Hyperkalemia in neonatal diarrheic calves depends on the degree of dehydration and the cause of the metabolic acidosis but does not require the presence of acidemia. J. Dairy Sci. 96:7234-7244.

Trefz, F. M., A. Lorch, M. Feist, C. Sauter-Louis, and I. Lorenz. 2013b. The prevalence and clinical relevance of hyperkalaemia in calves with neonatal diarrhoea. Vet. J. 195:350-356.

Trefz, F. M., A. Lorch, J. Zitzl, A. Kutschke, G. Knubben-Schweizer, and I. Lorenz. 2015b. Effects of alkalinization and rehydration on plasma potassium concentrations in neonatal calves with diarrhea. J. Vet. Intern. Med. 29:696-704.

Tura, A., S. Sbrignadello, E. Succurro, L. Groop, G. Sesti, and G. Pacini. 2010. An empirical index of insulin sensitivity from short IVGTT: Validation against the minimal model and glucose clamp indices in patients with different clinical characteristics. Diabetologia 53:144-152.

Van Beaumont, W., J. E. Greenleaf, and L. Juhos. 1972. Disproportional changes in hematocrit, plasma volume, and proteins during exercise and bed rest. J. Appl. Physiol. 33:55-61.

Van Putten, J. P., T. Wieringa, and H. M. Krans. 1985. Low pH and ketoacids induce insulin receptor binding and postbinding alterations in cultured 3T3 adipocytes. Diabetes 34:744-750.

Walker, B. G., D. N. Phear, F. I. Martin, and C. W. Baird. 1963. Inhibition of insulin by acidosis. Lancet 2:964-965.

Weisberg, L. S. 2008. Management of severe hyperkalemia. Crit. Care Med. 36:3246-3251.

Weldon, A. D., N. S. Moise, and W. C. Rebhun. 1992. Hyperkalemic atrial standstill in neonatal calf diarrhea. J. Vet. Intern. Med. 6:294-297.

Whittaker, J., C. Cuthbert, V. Hammond, and K. G. Alberti. 1981. Impaired insulin binding to isolated adipocytes in experimental diabetic ketoacidosis. Diabetologia 21:563-568.

Whittaker, J., C. Cuthbert, V. A. Hammond, and K. G. Alberti. 1982. The effects of metabolic acidosis in vivo on insulin binding to isolated rat adipocytes. Metabolism 31:553-557.

Youn, J. H., and A. A. McDonough. 2009. Recent advances in understanding integrative control of potassium homeostasis. Annu. Rev. Physiol. 71:381-401. 